\title{
L'origine simienne africaine des virus HIV à nouveau en vedette
}

\section{Les nouvelles de ce numéro ont été préparées par Jean-Claude Dreyfus Hélène Gilgenkrantz Jean-Pierre Grünfeld Axel Kahn Marc Peschanski}

1. Hirsch VM, Olmsted RA, Murphey-Cord M, Purcell RH, Johnson PR. An african primate lentivirus $\left(\mathrm{SIV}_{\mathrm{sm}}\right)$ closely related to HIV-2. Nature 1989; 339: 389-92.

2. Doolittle F. The simian-human connection. Nature 1989 ; 339 : 338-9.

$\mathrm{m} / \mathrm{s} n^{\circ} 7 \mathrm{vol} .5$, septembre 89
On connaît, à l'heure actuelle, plusieurs types de virus de type SIV (simian immunodeficiency virus), équivalents, chez les primates non humains, de HIV chez l'homme, à cette exception notable près qu'ils n'entraînent pas de déficit immunitaire chez leurs hôtes habituels.

SIV $_{\text {mac }}$, découvert chez des macaques en captivité, est extrêmement voisin de HIV-2 de l'Ouest africain, ce qui semblait fort bizarre, puisque l'habitat naturel de ce singe est l'Asie... où on ne connaît pas d'équivalent de ces virus $\mathrm{SIV}_{\mathrm{mac}} / \mathrm{HIV}$-2. Il semble en fait que les macaques aient été infectés en captivité, à la suite du contact avec un singe africain, vivant notamment dans l'Ouest africain, le mangabey (plus connu sous le nom de cercocèbe) couleur de suie (sooty mangabey).

Hirsch et ses collaborateurs, travaillant dans trois laboratoires du Maryland (USA), viennent de décrire chez des sooty mangabey un nouveau virus dénommé $\mathrm{SIV}_{\mathrm{sm}}$ dont la séquence est très proche de celle du virus HIV-2... et plus encore de $\operatorname{SIV}_{\text {mac }}$ (les divergences de $\mathrm{SIV}_{\mathrm{sm}}$ avec $\mathrm{SIV}_{\mathrm{mac}}$ et HIV-2 sont, pour le gène gag, supérieures à, respectivement, 12 et $27 \%$ ) ; compte tenu de la rapide évolution du génome de ces lentivirus, et contrairement à une opinion dont nous nous faisions récemment l'écho $\left(\mathrm{m} / \mathrm{s}, n^{\circ} 7\right.$, vol. 4 , p. 447), ces données suggèrent une séquence d'événements débutant par un ancêtre commun à $\mathrm{SIV}_{\mathrm{sm}}$ et $\mathrm{HIV}$-2, passant probablement du singe à l'homme il y a environ quarante ans en Afrique de l'Ouest. Ultérieurement, en captivité, un mangabey/cercocebes aurait pu infecter des macaques.

Il n'existe pas, pour HIV-1, d'indication aussi fortement en faveur d'une origine simienne, les différences entre ce virus et SIV $_{\text {agm }}$ (SIV du singe vert, african green monkey) étant plus importantes que celles entre SIV $_{\text {sm }}$ et HIV. 2. Deux arguments militent cependant en faveur d'une telle transmission, survenue il y a quelques dizaines d'années en Afrique: d'une part, la vitesse d'évolution des virus de cette famille (les lentivirus) est intégralement compatible avec ces hypothèses, d'autant que le rétrovirus qui ressemble le plus à HIV-1, fréquent en Afrique centrale, est SIV $_{\text {agm }}$, infectant le singe vert d'Afrique centrale (de même que $\operatorname{SIV}_{\mathrm{sm}}$ est le lentivirus le plus proche de HIV-2, tous deux étant trouvés en Afrique de l'Ouest). D'autre part, la pathogénicité des HIV chez l'homme est un argument en faveur du caractère récent de l'infection de l'espèce. SIV $_{\mathrm{sm}}$ est ainsi non pathogène chez les mangabey/cercocèbes... mais pathogène chez les macaques, de même que SIV $_{\mathrm{agm}}$, non pathogène pour le singe vert, est cytopathique pour des cellules humaines en culture. Cela suggère que ces lentivirus sont non pathogèries pour des hôtes auxquels ils sont adaptés depuis longtemps... mais le deviennent pour des hôtes nouveaux. Peut-être y-a-t-il un rapport entre cette constatation et l'impression que les signes pathologiques sont secondaires à l'apparition de formes «défectives » de virus $\left(\mathrm{m} / \mathrm{s}, n^{\circ} 6\right.$, vol. $5, p .424$. En cas d'adaptation à long terme, peut-être les génomes viraux subissent-ils moins souvent, au cours de leur cycle réplicatif, ces modifications brutales, délétionnelles, qui pourraient être responsables de la maladie de l'hôte récent?

A.K.

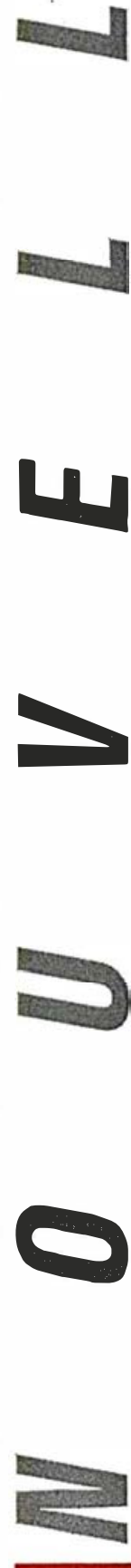

